\title{
Comprehensive Study of the Organic-Solvent-Free CDI-Mediated Acylation of Various Nucleophiles by Mechanochemistry**
}

\author{
Thomas-Xavier Métro, ${ }^{*}$ Julien Bonnamour, Thomas Reidon, Anthony Duprez, \\ Jordi Sarpoulet, Jean Martinez, and Frédéric Lamaty*a]
}

In memory of Professor Bertrand Castro

\begin{abstract}
Acylation reactions are ubiquitous in the synthesis of natural products and biologically active compounds. Unfortunately, these reactions often require the use of large quantities of volatile and/or toxic solvents, either for the reaction, purification or isolation of the products. Herein we describe and discuss the possibility of completely eliminating the use of organic solvents for the synthesis, purification and isolation of products resulting from the acylation of amines and other nucleophiles. Thus, utilisation of $N, N^{\prime}$-carbonyldiimidazole (CDI) allows efficient coupling between carboxylic acids and various nucleophiles under solvent-free
\end{abstract}

mechanical agitation, and water-assisted grinding enables both the purification and isolation of pure products. Critical parameters such as the physical state and water solubility of the products, milling material, type of agitation (vibratory or planetary) as well as contamination from wear are analysed and discussed. In addition, original organic-solvent-free conditions are proposed to overcome the limitations of this approach. The calculations of various green metrics are included, highlighting the particularly low environmental impact of this strategy.

\section{Introduction}

Acylation reactions are widely used in the synthesis of natural products and biologically active molecules, ${ }^{[1]}$ but they usually require large amounts of volatile and toxic solvents such as $\mathrm{N}, \mathrm{N}$-dimethylformamide or dichloromethane to be performed with efficiency. Indeed, a SciFinder survey of 680000 amidation reactions has shown that $83 \%$ of the reactions involve the use of either DMF (47\%) or $\mathrm{CH}_{2} \mathrm{Cl}_{2}(36 \%){ }^{[2]}$ The removal of organic solvents from the reaction media to reduce environmental impact would be highly attractive as they account for the major part of the material used to manufacture active pharmaceutical ingredients. ${ }^{[3]}$ Unfortunately, solvent-free synthesis under classical batch stirring often implies either solid or highly viscous reaction mixtures along with mass-transfer limitations. In a wide number of examples, these difficulties could be efficiently overcome by using mechanically induced agitation provided by ball mills from the laboratory to the pilot

[a] Dr. T.-X. Métro, Dr. J. Bonnamour, T. Reidon, A. Duprez, J. Sarpoulet, Prof. Dr. J. Martinez, Dr. F. Lamaty

Institut des Biomolécules Max Mousseron (IBMM)

UMR 5247, CNRS, Université Montpellier, ENSCM

Université de Montpellier, Campus Triolet

Place Eugène Bataillon, 34095 Montpellier Cedex 5 (France)

E-mail:txmetro@univ-montp2.fr

frederic.lamaty@univ-montp2.fr

[**] $C D I=\mathrm{N}, \mathrm{N}^{\prime}$-carbonyldiimidazole scale. ${ }^{[4]}$ Although enabling organic reactions to be performed in the absence of solvents, the recovery of the reaction mixture from the milling jar is often performed with the use of an organic solvent, raising questions concerning the "solvent-free" denomination of such processes. For our part, we have developed a strategy allowing the complete elimination of organic solvents in the synthesis, purification and isolation of products resulting from the acylation of amines and other nucleophiles. Other methods avoiding the use of organic solvent from reaction to product recovery have been previously published but they remain scarce. As an example, solvent-free recovery by the sublimation of nitrosobenzenes resulting from a reaction performed in a ball mill was described recently. ${ }^{[5]}$ Although carried out in the total absence of any organic solvent, this approach is limited to molecules presenting high vapour pressure properties. In some studies, the reaction mixture has been recovered from a ball mill reactor by using a cyclone under inert gas flow or by physical withdrawal directly from the milling jar followed by drying. ${ }^{[6]}$ When water-soluble inorganic salts were produced during the course of the reaction, they were removed by washing with water and/or trituration followed by filtration and drying, thereby avoiding the use of organic solvents. ${ }^{[7]}$ Unfortunately, these approaches were limited to addition or condensation reactions in which water or water-soluble inorganic salts were the only by-products. More recently, Štrukil et al. described the mechano-mediated synthesis of aromatic amides and dipeptides by using $N$-ethyl- $N^{\prime}$-(3-dimethylaminopropyl)carbodiimide hydrochloride $(E D C \cdot H C l)$ as coupling agent, nitromethane and $\mathrm{NaCl}$ as grinding assistants, 4-dimeth- 
ylaminopyridine (DMAP) as base and water to recover and purify the final products. ${ }^{[8]}$ Although water-based treatment and filtration are critical steps for the success of such organicsolvent-free processes, ${ }^{\left[{ }^{[9]}\right.}$ to the best of our knowledge, limitations concerning the water solubility and physical state (solid or liquid) of the products have never been considered or discussed previously. In addition, contamination from wear of the milling material is a phenomenon that has been widely described and analysed for other applications, but not for milling-mediated organic synthesis. ${ }^{[10]}$ Although critical for the purity of organic molecules synthesised by ball-milling in the complete absence of organic solvent from reaction to product isolation, product contamination from wear of milling material has never been analysed and discussed in depth. ${ }^{[11]}$ For our part, we have previously described the mechanosynthesis of amides from carboxylic acids and amine hydrochlorides by treatment with $N, N^{\prime}$-carbonyldiimidazole (CDI) without using organic solvent from reaction to product recovery. ${ }^{[12]}$ Pursuing our efforts to provide the organic chemistry community with a set of solutions enabling to avoid the use of problematic solvents, ${ }^{[13]}$ we herein describe a comprehensive study of the organic-solvent-free CDI-mediated acylation of $\mathrm{N}-, \mathrm{O}-, \mathrm{S}-$ and $\mathrm{C}$ nucleophiles by mechanochemistry, including analysis, discussion and solutions to limitations related to 1) the physical state and water solubility of the products and 2) contamination from wear.

\section{Results and Discussion}

\section{Optimisation of the reaction based on stoichiometry and amine acidic/basic form}

In most cases, coupling carboxylic acids with amine hydrochlorides in the presence of CDI has the advantage of producing easily separable compounds, namely solid hydrophobic amides, gaseous carbon dioxide and water-soluble by-products (carboxylic acids, imidazole and amines, the last two existing either as free bases or as hydrochloride salts). Thus, the treatment of hydrocinnamic acid with 1.0 equivalent of CDI in a $12 \mathrm{~mL}$ stainless-steel jar containing fifty $5 \mathrm{~mm}$ diameter balls in a planetary ball mill agitated at $500 \mathrm{rpm}$ for 5 min furnished the corresponding acylimidazole (Scheme 1).

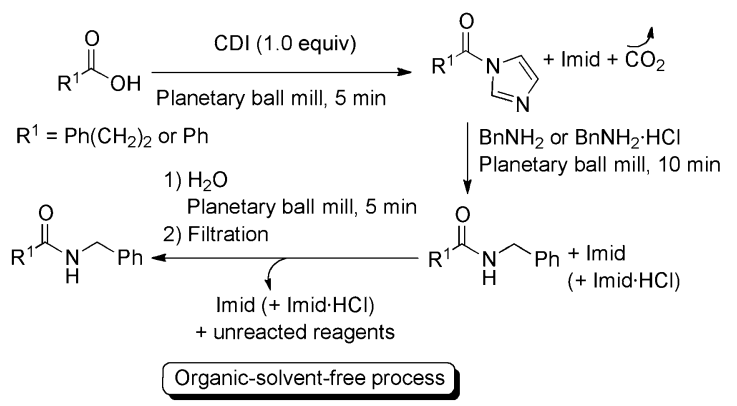

Scheme 1. Mechanosynthesis of $N$-benzylamides from carboxylic acids and CDI.
The latter was not isolated but its formation was followed by ex situ IR analysis of reaction samples. ${ }^{[14]}$ These samples were taken directly from the milling jar, immediately after the 5 min ball-milling had ended. They were analysed as such, without any solubilisation process. Thus, the disappearance of the hydrocinnamic acid IR band at $1692 \mathrm{~cm}^{-1}$ was observed along with the appearance of the acylimidazole IR band at $1730 \mathrm{~cm}^{-1}$ (Figure 1). The addition of 1.0 equivalent of benzyl-

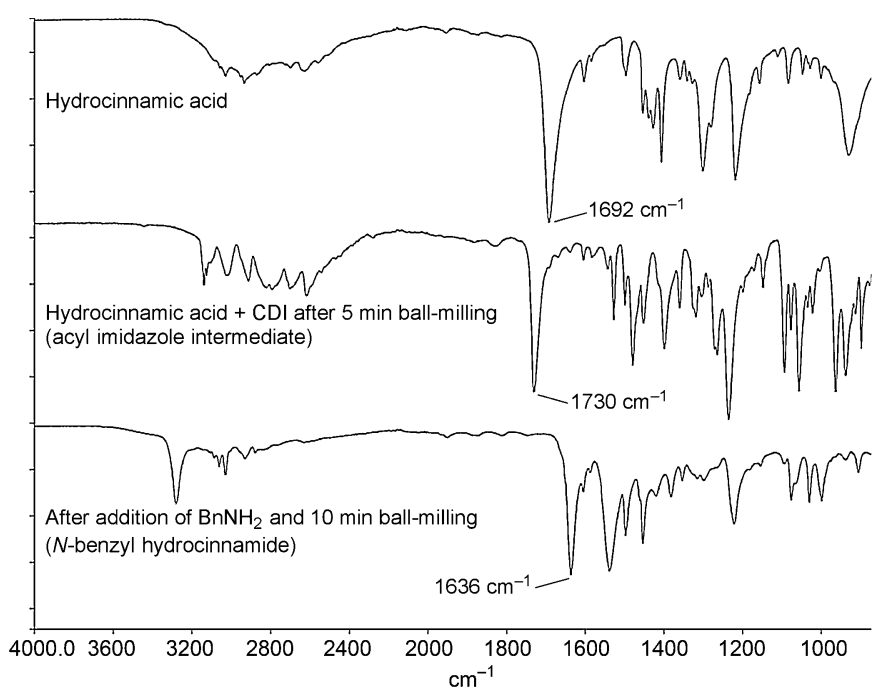

Figure 1. IR spectra for the mechanosynthesis of $N$-benzylhydrocinnamide. IR spectrum of hydrocinnamic acid (top); IR spectrum after mixing hydrocinnamic acid with CDI for 5 min (middle); IR spectrum after addition of $\mathrm{BnNH}_{2}$ and mixing for $10 \mathrm{~min}$ (bottom).

amine followed by mixing for 10 min led to the complete consumption of the acylimidazole, as indicated by the disappearance of its IR band at $1730 \mathrm{~cm}^{-1}$ and the formation of $\mathrm{N}$-benzylhydrocinnamide (new IR band at $1636 \mathrm{~cm}^{-1}$ ). The addition of deionised water to the jar followed by mixing for 5 min provided a suspension that could easily be transferred onto a glass frit, allowing separation of non-soluble $\mathrm{N}$-benzylhydrocinnamide from the by-products (imidazole and possible traces of hydrocinnamic acid and benzylamine). Drying under vacuum over $\mathrm{P}_{2} \mathrm{O}_{5}$ furnished pure $\mathrm{N}$-benzylhydrocinnamide in a yield of $76 \%$ (Table 1, entry 1 ). Interestingly, using benzyl-

Table 1. Optimisation of CDI-mediated mechanosynthesis of $\mathrm{N}$-benzylhydrocinnamide and $\mathrm{N}$-benzylbenzamide. ${ }^{[\mathrm{a}]}$

\begin{tabular}{|lllll|}
\hline Entry & Carboxylic acid & Amine & $\begin{array}{l}\text { Amine } \\
\text { [equiv] }\end{array}$ & $\begin{array}{l}\text { Isolated yield } \\
{[\%]}\end{array}$ \\
\hline 1 & hydrocinnamic acid & $\mathrm{BnNH}_{2}$ & 1.0 & 76 \\
2 & & $\mathrm{BnNH}_{2} \cdot \mathrm{HCl}$ & 1.0 & 82 \\
3 & $\mathrm{BnNH}_{2}$ & 0.9 & 76 \\
4 & $\mathrm{BnNH}_{2} \cdot \mathrm{HCl}$ & 0.9 & 94 \\
5 & $\mathrm{BnNH}_{2} \cdot \mathrm{HCl}$ & 0.9 & 88 \\
6 & $\mathrm{BnNH}_{2}$ & 0.9 & 73 \\
7 & & $\mathrm{BnNH}_{2} \cdot \mathrm{HCl}$ & 0.9 & $82^{\text {[b] }}$ \\
\hline [a] Performed on a $1.35 \mathrm{mmol}$ scale. [b] Performed on a $2.7 \mathrm{mmol}^{2}$ scale. \\
\hline
\end{tabular}


amine hydrochloride salt (instead of benzylamine) provided $\mathrm{N}$ benzylhydrocinnamide with an improved yield of $82 \%$ (Table 1, entry 2). Although the yield was not improved by using 0.9 equivalents of benzylamine (Table 1 , entry 3 ), the treatment of hydrocinnamic acid with 1.0 equivalent of CDI followed by the addition of 0.9 equivalents of benzylamine hydrochloride furnished $N$-benzylhydrocinnamide in a yield of $94 \%$ (Table 1 , entry 4). This $12 \%$ increase in reaction yield might be explained by a higher conversion of $\mathrm{BnNH}_{2} \cdot \mathrm{HCl}$ when hydrocinnamic acid and CDI were used in excess (Table 1, entry 4) compared with when hydrocinnamic acid, $\mathrm{CDI}$ and $\mathrm{BnNH}_{2} \cdot \mathrm{HCl}$ were utilised in equimolar amounts (Table 1, entry 2). It was hypothesised that the $10 \%$ excess of acylimidazole was hydrolysed to hydrocinnamic acid and imidazole during ball-milling with water and eliminated in the filtrate during the filtration step. This hypothesis was confirmed by HPLC analysis, which revealed the presence of both hydrocinnamic acid and imidazole in the filtrate. When hydrocinnamic acid was replaced with benzoic acid, $\mathrm{N}$-benzylbenzamide was obtained in a yield of $88 \%$ (Table 1, entry 5). As for the hydrocinnamic acid, the use of benzylamine as a free base furnished $\mathrm{N}$-benzylbenzamide in a lower yield of $73 \%$ (Table 1, entry 6).

Finally, increasing the filling ratio by performing the same reaction on a larger scale $(2.7 \mathrm{mmol}$ instead of $1.35 \mathrm{mmol})$ in the same combination of jar and balls furnished the amide in a slightly lower yield of $82 \%$ (Table 1, entry 7). It appears that after optimisation of these latter parameters, optimal yields were obtained when carboxylic acid was treated with 1.0 equivalent of $\mathrm{CDI}$ in a $12 \mathrm{~mL}$ stainless-steel jar containing fifty $5 \mathrm{~mm}$ diameter balls followed by the addition of 0.9 equivalents of benzylamine hydrochloride on a $1.35 \mathrm{mmol}$ scale (Table 1, entries 4 and 5).

\section{Influence of milling material on reaction efficiency and con- tamination from wear}

As these amides were isolated without being solubilised and filtered, one could wonder about the presence of contaminants arising from wear of the balls and container. ${ }^{[10]}$ To address this point, the content of metal contaminant in N-benzylbenzamide was measured either by inductively coupled plasma mass spectrometry (ICP-MS) or by gravimetric analysis. When the standard procedure was applied to the synthesis of $\mathrm{N}$-benzylbenzamide, ICP-MS analysis indicated the presence of very low amounts of the two main components of the stainless-steel grinding jar (366 ppm Fe and 169 ppm Cr; Table 2, entry 1). ${ }^{[15]}$ As expected, solubilising the product in EtOAc followed by filtration either through cotton or through a $0.2 \mu \mathrm{m}$ PTFE filter eliminated the contaminants to such an extent that neither iron nor chromium were detectable by ICP-MS analysis (Table 2, entries 2 and 3). In this case, using an organic solvent can be regarded as lowering the interest of the present methodology. Nevertheless, it has to be noted that in this peculiar situation, the only property expected from the organic solvent is to be able to solubilise the product, which leaves the chemist with a large number of possibilities in the choice of acceptable solvent.
We next evaluated the efficiency of this approach in a vibratory ball mill. Thus, utilising a $10 \mathrm{~mL}$ screw-top stainless-steel jar equipped with two $10 \mathrm{~mm}$ diameter stainless-steel balls agitated at $30 \mathrm{~Hz}$ within a vibratory ball mill furnished $\mathrm{N}$-benzylbenzamide in a yield of $85 \%$ (Table 2, entry 4). Unfortunately, ICP-MS analysis of the product revealed higher amounts of iron and chromium than when using the planetary ball mill (1400 ppm Fe and 1000 ppm Cr; Table 2, entry 4). When using a smaller container and balls $(5 \mathrm{~mL}$ jar and two $5 \mathrm{~mm}$ diameter balls), both the iron and chromium content in the product were lower (642 ppm Fe and $176 \mathrm{ppm} \mathrm{Cr}$; Table 2, entry 5), which can be explained by a lower intensity of collisions between the balls and walls. ${ }^{[10]}$ The previous experiments were realised in jars that had been used several times, and we expected to reduce contamination by using jars that had never been used before. Unfortunately, higher metal contamination was observed when $\mathrm{N}$-benzylbenzamide was synthesised in brand new jars (Table 2, entry 6 vs. entry 4 and entry 7 vs. entry 5). This phenomenon could be explained by the presence of fragilities on the metallic surface created during machining of the milling material. These fragilities would disappear after a few hours of milling. In these experiments, the lower yields of $\mathrm{N}$-benzylbenzamide can be explained by material losses during jar manipulation due to a less hermetic closure system compared with the screw-top jars utilised previously (59 vs. $85 \%$ in $10 \mathrm{~mL}$ jars and $67 \mathrm{vs}$. $75 \%$ in $5 \mathrm{~mL}$ jars). It was next envisaged to reduce contamination from wear by performing reactions with milling material lighter than stainless steel $\left(\rho_{\text {stainless steel }}=7.8 \mathrm{~g} \mathrm{~cm}^{-3}\right)$. Thus, changing the jar material to $\mathrm{ZrO}_{2}\left(\rho_{\text {zirconium oxide }}=5.9 \mathrm{~g} \mathrm{~cm}^{-3}\right)$ furnished $\mathrm{N}$-benzylbenzamide with a satisfying yield of $86 \%{ }_{1}^{[16]}$ albeit as a powder containing 12200 ppm zirconium (Table 2, entry 8). On the other hand, the lowest contamination resulting from wear was obtained when using a planetary ball mill with the jar and balls made of agate, a much lighter milling material than stainless steel $\left(\rho_{\text {agate }}=2.65 \mathrm{~g} \mathrm{~cm}^{-3}\right)$. Indeed, less than $100 \mathrm{ppm}$ silicon and $48 \mathrm{ppm}$ iron were obtained in $\mathrm{N}$-benzylbenzamide when the reaction was performed with the jar and balls made from agate (Table 2, entry 9). ${ }^{[15]}$ Although the yield was slightly lower in this case $(67 \%)$, completion of the reaction indicated that heavy balls such as those made of stainless steel were not mandatory for the success of this CDI-mediated mechanosynthesis of $N$-benzylbenzamide. Indeed, performing the same reaction in a $25 \mathrm{~mL}$ PTFE jar containing one $10 \mathrm{~mm}$ diameter PTFE ball with a steel core $\left(\rho_{\text {PTFE ball }}=3.3 \mathrm{~g} \mathrm{~cm}^{-3}\right)$ also produced $\mathrm{N}$-benzylbenzamide in a yield of $69 \%$ (Table 2, entry 10 ). Because under these conditions wear produced PTFE particles, the contaminant content was quantified by gravimetric analysis. This indicated that $2400 \mathrm{ppm}$ contaminant was present in $\mathrm{N}$-benzylbenzamide when produced with PTFE milling material (Table 2, entry 10). To our delight, it was discovered that even lighter milling material such as rubber can induce the mechanosynthesis of $N$-benzylbenzamide $\left(\rho_{\text {rubber }} \approx 1.3 \mathrm{~g} \mathrm{~cm}^{-3}\right)$. Thus, utilising an $18 \mathrm{~mm}$ diameter rubber ball in a PTFE jar furnished $\mathrm{N}$-benzylbenzamide in a yield of $80 \%$ (Table 2, entry 11 ). In this case, gravimetric analysis of the product indicated a contaminant content of less than $1000 \mathrm{ppm}$. As the reliability of gravi- 


\begin{tabular}{|c|c|c|c|c|c|c|c|c|c|}
\hline Entry & $\begin{array}{l}\text { Material \& size } \\
\text { of jar }\end{array}$ & $\begin{array}{l}\text { Material, number \& } \\
\text { diameter of balls }\end{array}$ & \multicolumn{4}{|c|}{$\begin{array}{l}\text { 1) } \mathrm{CDI}(1.0 \text { equiv), Ball mill, } 5 \mathrm{~min} \\
\text { 2) } \mathrm{BnNH} \cdot \mathrm{HCl}(0.9 \text { equiv) } \\
\text { Ball mill, } 10 \text { min } \\
\text { 3) } \mathrm{H}_{2} \mathrm{O} \text {, Ball mill, } 5 \mathrm{~min} \\
\text { 4) Filtration and drying } \\
\text { Yield and analysis of contaminant content }\end{array}$} & $\begin{array}{l}\text { Yield } \\
{[\%]}\end{array}$ & $\begin{array}{l}\text { Type of } \\
\text { analysis }\end{array}$ & $\begin{array}{l}\text { Contaminant con- } \\
\text { tent in ppm (metal) }\end{array}$ \\
\hline 1 & $\begin{array}{l}\text { stainless steel, } \\
12 \mathrm{~mL}\end{array}$ & $\begin{array}{l}\text { stainless steel, } \\
50 \times 5 \mathrm{~mm}\end{array}$ & planetary & used & suspension in $\mathrm{H}_{2} \mathrm{O}$ and filtration & 1.35 & 88 & ICP-MS & $366(\mathrm{Fe}) ; 169(\mathrm{Cr})$ \\
\hline 2 & & & & & $\begin{array}{l}\text { solubilised in EtOAc and filtered } \\
\text { through cotton }\end{array}$ & & & ICP-MS & $<30(\mathrm{Fe}) ;<30(\mathrm{Cr})^{[\mathrm{a]}}$ \\
\hline 3 & & & & & $\begin{array}{l}\text { solubilised in EtOAc and filtered } \\
\text { through } 0.2 \mu \mathrm{m} \text { PTFE filter }\end{array}$ & & & ICP-MS & $<30(\mathrm{Fe}) ;<30(\mathrm{Cr})^{[\mathrm{a}]}$ \\
\hline 5 & $\begin{array}{l}\text { stainless steel, } \\
5 \mathrm{~mL} \text { screw-top }\end{array}$ & $\begin{array}{l}\text { stainless steel, } \\
2 \times 5 \mathrm{~mm}\end{array}$ & & used & & 0.56 & 75 & ICP-MS & $642(\mathrm{Fe}) ; 176(\mathrm{Cr})$ \\
\hline 6 & $\begin{array}{l}\text { stainless steel, } \\
10 \mathrm{~mL}\end{array}$ & $\begin{array}{l}\text { stainless steel, } \\
2 \times 10 \mathrm{~mm}\end{array}$ & & new & & 1.13 & 59 & ICP-MS & $7400(\mathrm{Fe}) ; 1400(\mathrm{Cr})$ \\
\hline 7 & $\begin{array}{l}\text { stainless steel, } \\
5 \mathrm{~mL}\end{array}$ & $\begin{array}{l}\text { stainless steel, } \\
2 \times 5 \mathrm{~mm}\end{array}$ & & new & & 0.56 & 67 & ICP-MS & $1200(\mathrm{Fe}) ; 314(\mathrm{Cr})$ \\
\hline 8 & $\begin{array}{l}\mathrm{ZrO}_{2}, 10 \mathrm{~mL} \\
\text { screw-top }\end{array}$ & $\mathrm{ZrO}_{2}, 2 \times 12 \mathrm{~mm}$ & & used & & 1.13 & $86^{[\mathrm{b}]}$ & ICP-MS & $\begin{array}{l}151(\mathrm{Fe}) ; 12200(\mathrm{Zr}) ; \\
740(\mathrm{Y})\end{array}$ \\
\hline 9 & agate, $50 \mathrm{~mL}$ & agate, $4 \times 12 \mathrm{~mm}$ & planetary & & & 2.7 & 67 & ICP-MS & $<100(\mathrm{Si}) ;{ }^{[\mathrm{a}]} 48(\mathrm{Fe})$ \\
\hline 10 & $\begin{array}{l}\text { PTFE, } 25 \mathrm{~mL} \\
\text { screw-top }\end{array}$ & $\begin{array}{l}\text { PTFE with steel core, } \\
1 \times 10 \mathrm{~mm}\end{array}$ & vibratory & & & 5.0 & $69^{[c]}$ & gravimetric & 2400 \\
\hline 11 & $\begin{array}{l}\text { PTFE, } 25 \mathrm{~mL} \\
\text { screw-top }\end{array}$ & rubber, $1 \times 18 \mathrm{~mm}$ & & & & 1.35 & 80 & gravimetric & $<1000^{[\mathrm{a}]}$ \\
\hline 12 & $\begin{array}{l}\text { stainless steel, } \\
250 \mathrm{~mL}\end{array}$ & $\begin{array}{l}\text { stainless steel, } \\
50 \times 10 \mathrm{~mm}\end{array}$ & planetary & & & 22.5 & $92^{[\mathrm{b}]}$ & gravimetric & 42000 \\
\hline 13 & $\begin{array}{l}\text { stainless steel, } \\
250 \mathrm{~mL}\end{array}$ & rubber, $10 \times 18 \mathrm{~mm}$ & & & & 22.5 & $91^{[\mathrm{b}]}$ & gravimetric & 3400 \\
\hline
\end{tabular}

metric analysis performed on a $100 \mathrm{mg}$ sample is much lower than that of ICP-MS analysis, both the efficiency and wear resistance of the rubber milling material in the production of $\mathrm{N}$ benzylbenzamide was tested on a larger scale. First, the reaction was performed on a $22.5 \mathrm{mmol}$ scale in a $250 \mathrm{~mL}$ jar containing fifty $10 \mathrm{~mm}$ diameter stainless-steel balls, which produced $N$-benzylbenzamide in a yield of $92 \%,{ }^{[16]}$ albeit containing 42000 ppm metallic contaminants, as analysed by gravimetric analysis (Table 2, entry 12). Changing the stainless-steel balls to ten $18 \mathrm{~mm}$ diameter rubber balls furnished $\mathrm{N}$-benzylbenzamide in a yield of $91 \%$ with a much lower contaminant content of 3400 ppm (Table 2, entry 13). The higher contaminant content obtained with rubber balls on a $22.5 \mathrm{mmol}$ scale (Table 2, entry 13) compared with the contamination resulting from the experiment realised with one rubber ball on a $1.35 \mathrm{mmol}$ scale (Table 2, entry 11) can be explained by the higher intensity of collisions between the balls and walls. However, these results clearly show that contamination from wear can be substantially reduced by a judicious choice of milling material. As solvent-free organic syntheses often imply "soft" reaction mixtures, selecting lighter grinding materials instead of classical heavy materials such as stainless steel could greatly help in reducing the contaminant content of products issuing from procedures avoiding the use of organic solvent from reaction to product recovery.

\section{Influence of milling time on contamination from wear}

The influence of milling time on contamination content was also studied. The reaction mixture of the $\mathrm{N}$-benzylhydrocinnamide synthesis was sampled every $5 \mathrm{~min}$ and analysed by atomic absorption spectroscopy (AAS) to determine the iron content. Hydrocinnamic acid and $\mathrm{CDI}$ were first agitated for $5 \mathrm{~min}$ in the ball mill. After the addition of benzylamine followed by mixing for $5 \mathrm{~min}$, the iron content reached $190 \mathrm{ppm}$ (Figure 2). When the reaction mixture was sampled after 10 and 15 min of agitation, the iron content had increased to 216 and $319 \mathrm{ppm}$, respectively. These results confirm that contamination from wear increased with time, highlighting the importance of the optimisation of reaction time in completely solvent-free ball-mill-mediated organic syntheses to reduce product contamination from wear. This analytical study of the metal traces issuing from the wear of balls and container shows that as long as the presence of metal traces is compatible with the intended use of the products, synthesis and purification can be realised in the complete absence of organic sol- 

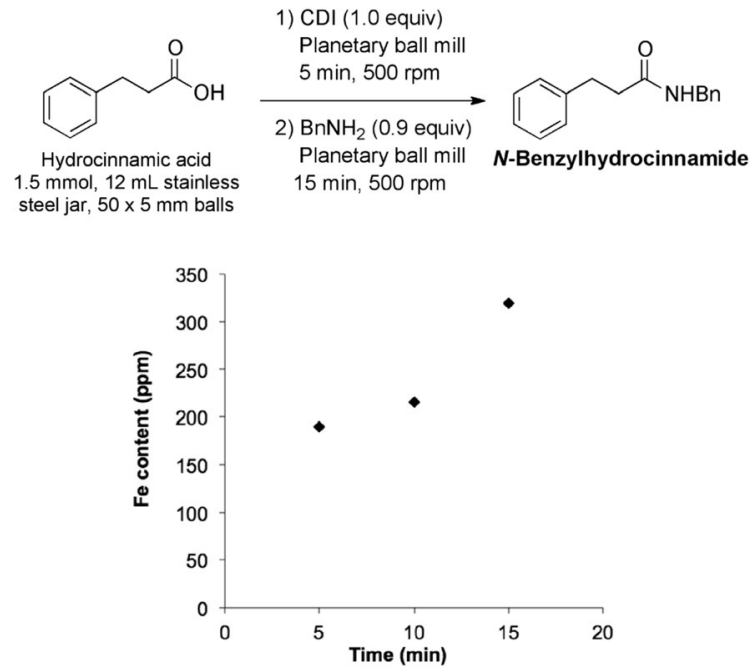

Figure 2. Iron content as a function of time during the synthesis of $\mathrm{N}$-benzylhydrocinnamide.

vents. If the presence of metal traces is inconsistent with the required use of the products, these impurities can be largely removed by solubilisation of the amide in a low-toxic solvent such as EtOAc followed by simple filtration. In addition, contamination from wear can be greatly reduced by an appropriate choice of milling material and by optimisation of milling time.

\section{Scope and limitations for acyla- tion of $\mathrm{N}$-nucleophiles}

To give a global view of the substrate scope and limitations of this approach, preliminary results from a study that we published previously have been included in the following discussion. ${ }^{[12]} \mathrm{Ap}$ plication of this approach to other carboxylic acids and amines was realised on the $1.35 \mathrm{mmol}$ scale in a $12 \mathrm{~mL}$ stainless-steel jar containing fifty $5 \mathrm{~mm}$ diameter balls under planetary ball-milling agitation. Linear carboxylic acids such as hexanoic acid, 4-phenylbutyric acid or phenylacetic acid reacted efficiently with $\mathrm{CDI}$ and benzylamine hydrochloride to furnish the corresponding amides in high yields (Table 3, compounds 1-3). It is worth noting here that neither a bromine atom nor a polar nitro group on the aromatic ring of phenylacetic acid prevented the amides $\mathbf{4}$ and $\mathbf{5}$ from being isolated in good yields (69 and $91 \%$, respectively; Table 3). Similarly, the treatment of $\alpha$-methylphenylacetic acid with CDI and benzylamine hydrochloride led to isolation of $\mathrm{N}$-benzyl-2-phenylpropanamide (6) in a yield of $70 \%$ (Table 3, compound 6). The higher yield of amide 3 (93\%) compared with that of amide 6 could be explained by a greater steric hindrance in 2-phenylpropionic acid compared with in phenylacetic acid. However, HPLC analysis revealed the presence of amide 6 in the aqueous filtrate. Thus, EtOAc extraction of the filtrate obtained from the synthesis of 6 followed by purification on silica gel led to an increased yield of 6 of $86 \%$. This result indicates that a lower yield of amide 6 (without extraction of the filtrate) could be explained by a higher water solubility of the product. Similarly, $\mathrm{CDI}$ activation of highly hindered acids such as 1-adamantanecarboxylic acid is not a limitation in this approach as the latter could be transformed into amide 7 in a good yield of $77 \%$ (Table 3). Primary amines other than benzylamine could also be acylated with high efficiency. Thus, phenethylamine and 2,4-dimethoxybenzylamine hydrochlorides furnished the corresponding amides in yields of 96 and $84 \%$, respectively (Table 3 ,

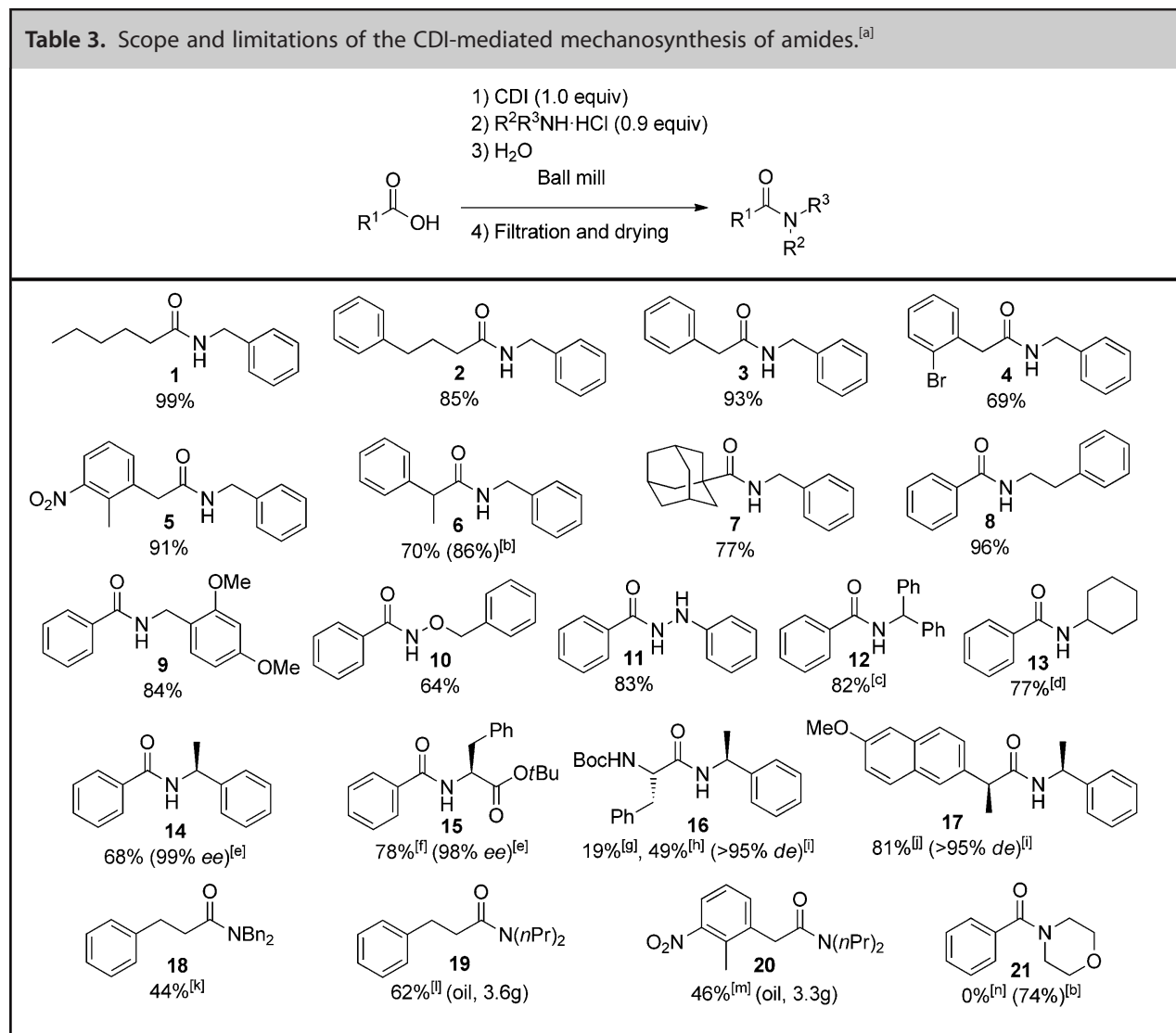

[a] Realised on a $1.35 \mathrm{mmol}$ scale unless otherwise noted. [b] After extraction of the aqueous phase with EtOAc. [c] Completed within 20 min. [d] Completed within 1.5 h. [e] Determined by chiral HPLC, see the Supporting Information for details. [f] Completed within $30 \mathrm{~min}$. [g] After agitation for 50 min with (S)methylbenzylamine hydrochloride on a $1.35 \mathrm{mmol}$ scale. [h] Completed within $30 \mathrm{~min}$ with (S)-methylbenzylamine on a $0.45 \mathrm{mmol}$ scale. [i] Determined by ${ }^{1} \mathrm{H}$ and ${ }^{13} \mathrm{C}$ NMR spectroscopy. No signal corresponding to the diastereoisomer was observed. [j] Realised with $0.5 \mathrm{mmol}$ of (S)-(+)-2-(6-methoxy-2-napthyl)propionic acid, 1.0 equiv of $\mathrm{CDI}$ and 1.9 equiv of $(S)$-methylbenzylamine. [k] Completed within $6 \mathrm{~h}$. [l] Completed within $3 \mathrm{~h}$. [m] Completed within $4 \mathrm{~h}$. [n] Completed within $3 \mathrm{~h} 10 \mathrm{~min}$. 
compounds 8 and 9). Non-hindered nitrogen nucleophiles such as $O$-benzyl hydroxylamine and phenylhydrazine were also efficiently benzoylated, furnishing amide 10 and hydrazide 11 in yields of 64 and $83 \%$, respectively. $\alpha$-Substituted primary amines reacted more slowly than non-substituted primary amines. Indeed, agitation of $20 \mathrm{~min}$ and $1.5 \mathrm{~h}$, respectively, were necessary to obtain the full conversion of benzoylimidazole intermediates when benzhydrylamine and cyclohexylamine hydrochlorides were used. Yet, the corresponding amides 12 and 13 were both isolated in good yields (82 and $77 \%$, Table 3 ). When enantiopure $\alpha$-substituted primary amines such as (S)- $\alpha$-methylbenzylamine and phenylalanine tert-butyl ester hydrochlorides were used as nucleophiles, the corresponding amides 14 and $\mathbf{1 5}$ were obtained as enantiopure compounds in yields of 68 and $78 \%$, respectively.

We next evaluated the stereoselectivity of the process with enantiopure carboxylic acids as starting materials. When $1.5 \mathrm{mmol}$ of Boc-protected L-phenylalanine was treated with 1.0 equivalent of $\mathrm{CDI}$ and then with 0.9 equivalents of $(S)-\alpha$ methylbenzylamine during $50 \mathrm{~min}$, the amide 16 was isolated in a very low yield (19\%), which can be explained by a sticky reaction media preventing efficient agitation of the reaction mixture (Table 3). This limitation could be solved by both performing the reaction on a $0.45 \mathrm{mmol}$ scale and by using $(S)-\alpha$ methylbenzylamine as a free base. Under these conditions, amide 16 was isolated in a yield of $49 \%$ without any loss of chirality as no signal corresponding to the diastereoisomer was observed by ${ }^{1} \mathrm{H}$ NMR spectroscopy. Similarly, the reaction of $1.5 \mathrm{mmol}$ of both enantiopure Naproxen and CDI followed by agitation with $1.35 \mathrm{mmol}$ of (S)- $\alpha$-methylbenzylamine hydrochloride furnished only traces of the amide 17. As previously, performing the CDI-mediated activation of Naproxen on a smaller scale $(0.5 \mathrm{mmol}$ in this case) followed by agitation with 1.9 equivalents of $(S)$ - $\alpha$-methylbenzylamine as a free base furnished the amide 17 in high yield (81\%) and diastereomeric excess (Table 3).

Coupling with secondary amines was next envisioned. The treatment of hydrocinnamic acid with CDI followed by the addition of dibenzylamine hydrochloride required agitation for $6 \mathrm{~h}$ to furnish amide 18 in a yield of $44 \%$ (Table 3). LC-MS analysis of the aqueous filtrate revealed no trace of amide 18 but the presence of both hydrocinnamic acid and dibenzylamine. Thus, the relatively low yield of $\mathbf{1 8}$ can be explained either by incomplete conversion of the starting materials or by partial hydrolysis of the hydrocinnamic acyl-imidazole during the process. The recovery of the product after agitation with water is efficient as long as the product is a solid. As N,N-di-n-propyl-3phenylpropanamide (19) is an oil that solubilises imidazole at ambient temperature, we envisaged carrying out the reaction on a larger scale to realise an organic-solvent-free treatment of the liquid reaction mixture. Indeed, performing the reaction with $25 \mathrm{mmol}$ of hydrocinnamic acid, 1.1 equivalents of CDI and 1.1 equivalents of di- $n$-propylamine allowed an easy transfer of the liquid reaction mixture directly into a Kugelrohr apparatus. Subsequent distillation followed by aqueous washings and drying produced $3.6 \mathrm{~g}$ of $\mathrm{N}, \mathrm{N}$-di-n-propyl-3-phenylpropanamide (19) in a yield of $62 \%$ (Table 3 ). The same approach starting from 2-methyl-3-nitrophenylacetic acid furnished $3.3 \mathrm{~g}$ of amide 20 in a moderate yield of $46 \%$, slightly better than that previously reported in the literature using a different strategy. ${ }^{[17]}$ It is worth noting that in these cases distillation of the reaction mixture would also efficiently eliminate any contaminant issuing from wear. Another requirement for the success of this approach is the hydrophobicity of the products. When coupling benzoic acid with morpholine, the reaction mixture was completely solubilised after the addition of water to the jar, excluding filtration as a way to recover the product. Yet, EtOAc extractions of this aqueous homogeneous phase furnished $\mathrm{N}$-benzoylmorpholine (21) in a yield of $74 \%$ (Table 3). This result shows that the solubility of amide $\mathbf{2 1}$ in water prevented its organic-solvent-free recovery and purification, but not its formation from benzoic acid, CDI and morpholine in the absence of solvent under mechanically-mediated agitation.

We next explored the reactions with aniline derivatives, which are known to react sluggishly with acyl-imidazole intermediates. ${ }^{[18]}$ When 2-phenylpropionylimidazole, prepared from 2-phenylpropionic acid and CDI, was treated with aniline hydrochloride in the absence of solvent in a ball mill, the corresponding amide 22 was isolated in a yield of $91 \%$ after only 10 min of reaction (Table 4). It is worth noting that when performed in boiling $[0.39 \mathrm{M}]$ EtOAc, the same reaction required $3 \mathrm{~h}$ to reach $86 \%$ conversion. ${ }^{[19]}$

Similarly, $\mathrm{N}$-phenylbenzamide (23) was obtained in a yield of $93 \%$ after 10 min when the reaction was performed without solvent in a ball mill, whereas $1 \mathrm{~h}$ was necessary to reach $90 \%$ conversion when the reaction was realised in $\mathrm{N}$-methyl-2-pyrrolidone (NMP) at $50{ }^{\circ} \mathrm{C}$ (Table 4) ${ }^{[18]}$ As in solution, the presence of an electron-withdrawing group such as a trifluoromethyl or cyano group on the aromatic ring slowed the reaction. Indeed,

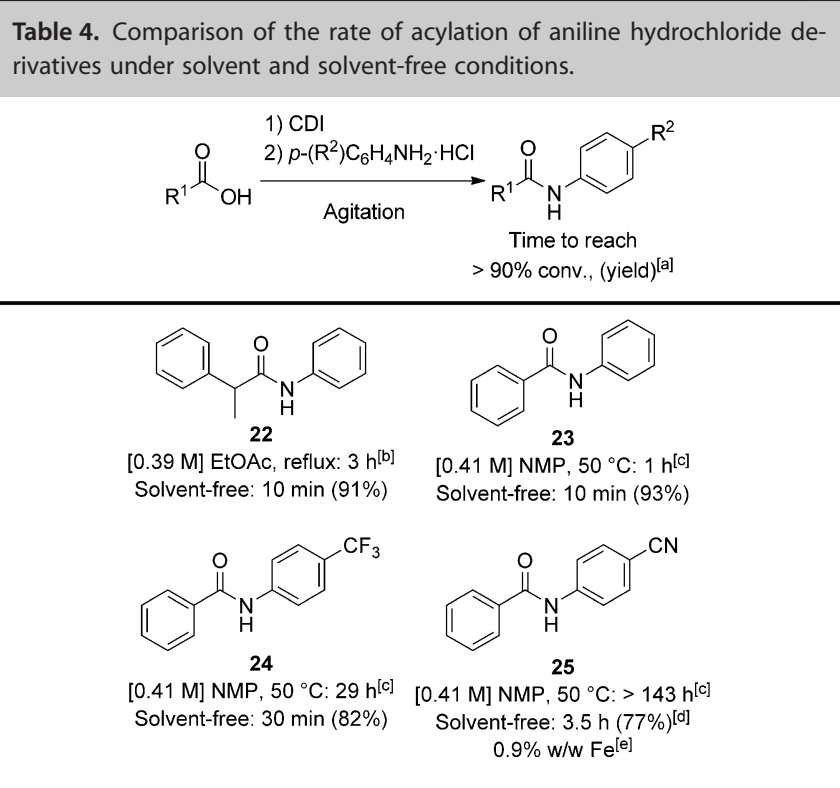

[a] Reaction time to reach $86 \%$ conversion for 22 and $>90 \%$ conversion for compounds 23-25. [b] See ref. [19]. [c] See ref. [18]. [d] From 4-aminobenzonitrile, yield corrected based on contaminant content. [e] Determined by AAS. 
$30 \mathrm{~min}$ and $3.5 \mathrm{~h}$ were required to produce amides 24 and 25 from $p$-trifluoromethylaniline hydrochloride and $p$-aminobenzonitrile, respectively (Table 4). Yet, these acylation reactions were still more rapid than in $[0.41 \mathrm{M}] \mathrm{NMP}$ at $50^{\circ} \mathrm{C}$; under these conditions, $29 \mathrm{~h}$ and more than $143 \mathrm{~h}$ were necessary to reach $90 \%$ conversion. It is worth noting that the contamination from wear in the case of the reaction of benzoylimidazole with $p$-aminobenzonitrile was relatively low $(0.9 \% \mathrm{w} / \mathrm{w})$ when considering that the ball-mill-mediated agitation was performed for $3.5 \mathrm{~h}$.

This approach was next applied to the production of the active metabolite of Leflunomide, ${ }^{[20]}$ which was approved for commercialisation under the name Teriflunomide (trade name Aubagio) by the FDA in 2012 for the treatment of multiple sclerosis. ${ }^{[21]}$ Indeed, the treatment of 5-methyl-4-isoxazolecarboxylic acid with CDI followed by mixing with 4-(trifluoromethyl)aniline hydrochloride during $5 \mathrm{~h}$ and then with water during $5 \mathrm{~min}$ produced Leflunomide as a fine suspension in water (Scheme 2). This amide was not isolated but submitted to hydrolysis under acidic conditions with magnetic stirring to furnish Teriflunomide in a yield of $81 \%$ after filtration and drying. AAS analysis of the final product revealed only low traces of iron (678 ppm). As one could expect higher wear contamination resulting from a relatively long grinding time, this low iron content could be explained by the partial oxidation of metallic particles during the acidic aqueous treatment, water solubilisation of the corresponding cations and elimination during the filtration step.

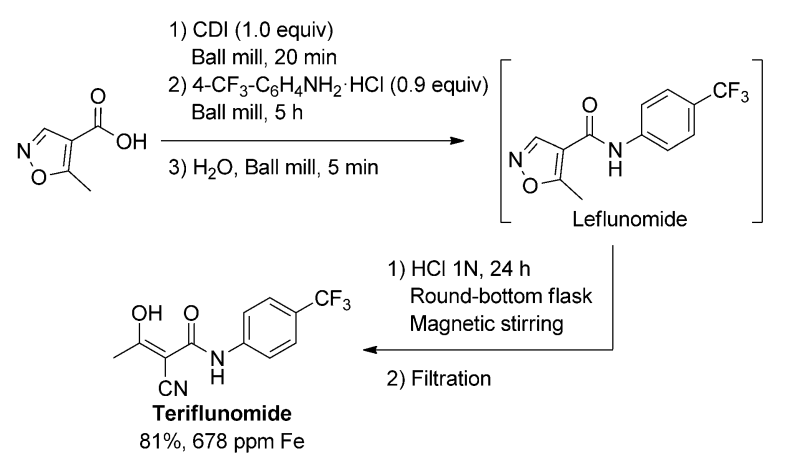

Scheme 2. Mechanosynthesis of Teriflunomide.

\section{Application to O-, S- and C-nucleophiles}

This organic-solvent-free CDI-mediated acylation strategy was also applied to other nucleophiles. Indeed, when benzoylimidazole resulting from $\mathrm{CDI}$ activation of benzoic acid was ballmilled with phenol, phenyl benzoate (26) was isolated in a yield of $84 \%$ (Table 5). Similarly, the treatment of benzoic acid with CDI in a vibratory ball mill agitated at $25 \mathrm{~Hz}$ followed by the addition of 3-nitrophenylmethanol furnished 3-nitrobenzyl benzoate (27) in a yield of $85 \%$ (Table 5). Phenyl 2-phenylpropanoate (28) was isolated in a yield of $80 \%$ by using the same approach, yet it had to be recovered from the milling jar with EtOAc due to its low melting point. Thiols could also be
Table 5. Examples of the organic-solvent-free CDI-mediated acylation of O-, S- and C-nucleophiles. ${ }^{[a]}$

$$
\begin{aligned}
& \text { 1) } \mathrm{CDI} \text {, Ball mill, } 5 \text { min } \\
& \text { 2) } \mathrm{O}, \mathrm{S} \text { or } \mathrm{C} \text { nucleophile } \\
& \text { Ball mill, } 10 \text { min }
\end{aligned}
$$

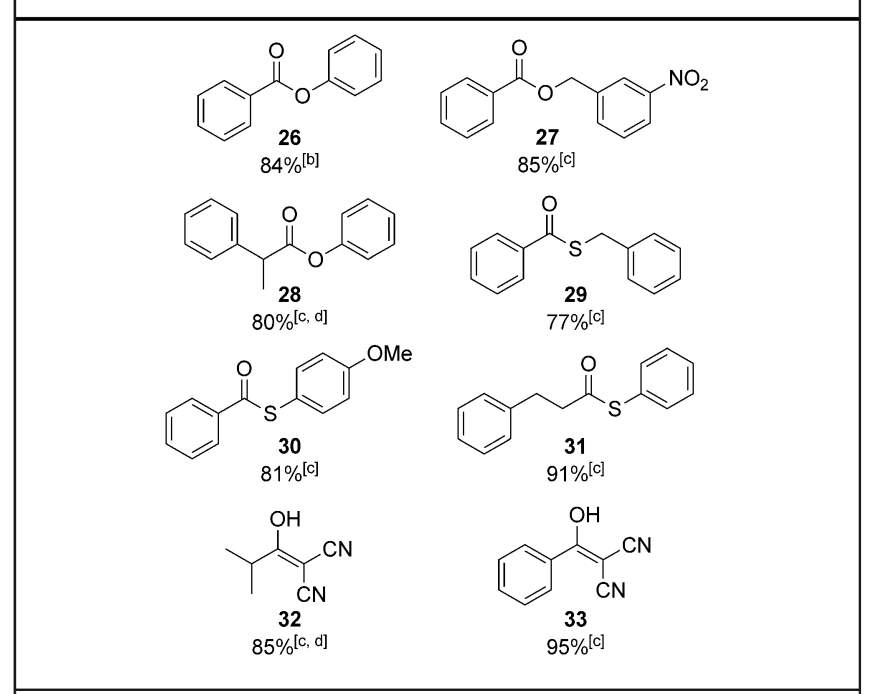

[a] Realised on a $1.35 \mathrm{mmol}$ scale. [b] Performed in a planetary mill rotated at $500 \mathrm{rpm}$. [c] Performed in a vibratory mill at $25 \mathrm{~Hz}$. [d] Recovered with EtOAc.

used as nucleophiles as phenylmethanethiol and 4-methoxybenzenethiol furnished the corresponding benzothioates 29 and $\mathbf{3 0}$ in yields of 77 and $81 \%$, respectively (Table 5). When 3phenylpropanoylimidazole was ball-milled with thiophenol, the corresponding S-phenyl 3-phenylpropanethioate (31) was isolated in a yield of $91 \%$.

We next envisioned applying this approach to C-nucleophiles. The first attempt using the 1,3-dione dimedone (5,5-dimethyl-1,3-cyclohexanedione) as the nucleophile did not furnish any acylated product (neither C- nor O-acylated). The addition of $\mathrm{N}, \mathrm{N}$-diisopropylethylamine (DIEA) as base to the reaction mixture did not lead to a successful reaction. In contrast, the treatment of isobutyroylimidazole resulting from the CDI activation of isobutyric acid with malononitrile furnished enol 32 in a yield of $85 \%$ (Table 5). Yet, the solubility of the product in both neutral and acidic water forced us to recover it from the aqueous phase by extraction with EtOAc. Finally, benzoic acid could be transformed into enol $\mathbf{3 3}$ in a yield of $95 \%$ after reaction with $\mathrm{CDI}$ followed by the addition of malononitrile (Table 5). Despite being completely solubilised after ball-milling with water, enol $\mathbf{3 3}$ could be recovered without using organic solvent by acidification of the aqueous reaction mixture and filtration of the resulting precipitate. These results show that, as long as the final products are solids and not soluble in water, O-, S- and C-nucleophiles can be acylated with high efficiency without using organic solvents from reaction to product recovery. 


\section{Evaluation of the environmental impact}

We then evaluated the environmental impact of this approach based on the mechanosynthesis of $\mathrm{N}$-benzylbenzamide and compared it with previously reported reaction conditions using various reagents: $\mathrm{N}, \mathrm{N}$-diisopropylbenzylamine-2-boronic acid (IBA), ${ }^{[22]} N, N^{\prime}$-dicyclohexylcarbodiimide (DCC), ${ }^{[23]}$ thionyl chloride $\left(\mathrm{SOCl}_{2}\right)_{,}^{[24]} \mathrm{N}, \mathrm{N}^{\prime}$-carbonyldiimidazole $(\mathrm{CDI})^{[25]}$ and sulfated tungstate. ${ }^{[26]}$ First of all, it has to be highlighted that $\mathrm{CDI}$ in THF under classical stirring or without solvent in a ball mill was the most efficient reagent as $\mathrm{N}$-benzylbenzamide was isolated in the highest yield ( $92 \%$, Table 6, entries 4 and 6). Yet, the use

Table 6. Comparison of the environmental impact of the various strategies for the synthesis of $\mathrm{N}$-benzylbenzamide.

\begin{tabular}{|c|c|c|c|c|c|c|c|}
\hline Entry & Reagent & $\begin{array}{l}\text { Yield } \\
\text { [\%] }\end{array}$ & $\begin{array}{l}\text { Atom econ- } \\
\text { omy [\%] }\end{array}$ & $\mathrm{sEF}^{[a]}$ & $\mathrm{cEF}^{[\mathrm{b}]}$ & $\begin{array}{l}\text { GHS picto- } \\
\text { grams }^{[c]}\end{array}$ & $\begin{array}{l}\text { Eco- } \\
\text { scale }^{[d]}\end{array}$ \\
\hline 1 & $\mathrm{IBA}^{[22]}$ & 50 & 92.1 & 2.38 & 396.2 & 8 & 44 \\
\hline 2 & $\mathrm{DCC}^{[23][\mathrm{e}]}$ & 82 & 48.5 & 2.75 & 66.1 & 8 & 62 \\
\hline 3 & $\mathrm{SOCl}_{2}^{[24][e]}$ & 72 & 60.6 & 2.32 & 24.6 & 8 & 54 \\
\hline 4 & $\begin{array}{l}C D I \text { in } \\
\text { THF }^{[25][e]}\end{array}$ & 92 & 54.0 & 2.01 & 41.9 & 9 & 67 \\
\hline 5 & $\begin{array}{l}\text { sulfated } \\
\text { tungstate }{ }^{[26]}\end{array}$ & 81 & 92.1 & 1.55 & 23.5 & 9 & 49.5 \\
\hline 6 & $\begin{array}{l}\text { solvent-free } \\
\text { CDI }\end{array}$ & 92 & 49.3 & 2.36 & 20.8 & 6 & 79 \\
\hline
\end{tabular}

[a] Simple E-factor [b] Complete E-factor. [c] Cumulative number of GHS pictograms. [d] See ref. [28]. [e] See ref. [26] for raw data.

of $C D I$ is detrimental to the atom economy of the reaction like other reagents that have to be used in stoichiometric quantities. Indeed, the atom economy is 54.0 and $49.3 \%$ when CDI is used in THF and without solvent, respectively (Table 6, entries 4 and 6). In contrast, the atom economy reaches $92.1 \%$ when catalysts such as IBA or sulfated tungstate are employed (Table 6, entries 1 and 5). The yield and atom economy are both simple and powerful parameters for evaluating the environmental impact of a reaction, but they omit critical issues such as the amounts of organic solvents and water required to perform the reaction and isolate the final product. Indeed, solvents and water account for 56 and $32 \%$, respectively, of the total mass of material used in the pharmaceutical industry. ${ }^{[3]}$ Although green metrics such as the environmental factor ( $E$ factor $)^{[27]}$ and process mass intensity $(\mathrm{PMI})^{[3]}$ have been developed to take into account the quantity of waste produced during a reaction or the total mass of materials required to obtain the final product, respectively, ${ }_{1}^{[3]}$ the lack of homogeneity in the consideration of water and organic solvents in the calculations by the chemistry community has led to confusion and difficulties in the interpretation of these parameters.

This observation led Roschangar et al. to propose definitions of the "simple E-factor" and the "complete E-factor" as well as their mode of utilisation. ${ }^{[29]}$ The simple E-factor (noted SEF) omits water and solvents in the calculations, whereas the complete E-factor (noted cEF) takes into account every material entering into the process without taking into consideration any water or organic-solvent recycling steps. With a simple E-factor value of 2.36, the organic-solvent-free CDI-mediated mechanosynthesis of $\mathrm{N}$-benzylbenzamide presents no clear advantage over the other strategies (Table 6). On the other hand, the CDImediated mechanosynthesis of $\mathrm{N}$-benzylbenzamide appears to be the most interesting approach when considering every material utilised (including water and organic solvent) with the lowest complete E-factor score of 20.8 (Table 6). Another very simple way to evaluate the environmental impact of an experimental procedure, especially for the chemist who is going to perform the reaction at the bench, is to look at the cumulative number of GHS pictograms of the materials he is going to manipulate. Considering all the strategies reported for the synthesis of $\mathrm{N}$-benzylbenzamide, our approach has a cumulative number of GHS pictograms of 6 , whereas for all the other strategies this number is equal to or greater than 8 (Table 6).

Finally, when considering the Eco-scale score, ${ }^{[28]}$ a green metric ranging from 0 (completely failed reaction) to 100 (ideal reaction) taking into account yield, cost, safety, technical setup, temperature and reaction time, workup and purification, the CDI-mediated mechanosynthesis of $\mathrm{N}$-benzylbenzamide has the highest score (79), which corresponds to an excellent synthesis. These excellent green metric scores can partially be explained by the use of non-toxic water in the process. One could argue that the utilisation of water, a precious resource on earth, results in the contamination of water with organic material, implying costly aqueous-phase post-treatments and an overall negative influence on the environmental impact of the process. Yet, to the best of our knowledge, none of the previously described acylation strategies have avoided water contamination with organic material, due to the systematic use of water washings to obtain pure acylated products. Consequently, environmental impact superiority of the present approach over classical strategies does not rely only on the use of water as an innocuous entity, but, inter alia, on its original and specific use (water-assisted ball-milling) enabling the complete elimination of organic solvents during the purification and recovery steps.

\section{Conclusion}

The acylation of amines and other nucleophiles can be efficiently performed in the absence of any organic solvent from reaction to product recovery when combining $\mathrm{CDI}$ activation of carboxylic acids and ball-milling agitation. This strategy is applicable to a wide range of carboxylic acids and nucleophiles provided that the corresponding final products are immiscible in water and that their contaminant contents are compatible with their intended use. However, we have shown that the amount of contaminant issuing from wear can be severely reduced by optimisation of the reaction time and appropriate choice of milling material. In particular, a "soft" reaction mixture, such as those frequently encountered in solvent-free or solventless organic syntheses, does not require dense milling materials. Indeed, utilising lighter milling material such as agate, PTFE, or even rubber enables a sharp reduction of contamination from wear without limiting the reaction efficiency. 
In the limited number of cases in which the products are soluble in water, organic-solvent-based extraction appears to be a convenient solution to the recovery of the final products from the aqueous phase, although preventing the whole process from being organic-solvent-free from reaction to product recovery. Yet, the absence of organic solvent during the reaction is still a decisive advantage as a tremendous reduction of the reaction time has been observed when performing the acylation of aniline derivatives under mechanical agitation. Finally, calculation and analysis of the various green metrics have shown that this approach can be an efficient way to mitigate the environmental impact of nucleophile acylation reactions.

\section{Experimental Section}

All reagents were purchased from Aldrich Chemical Co., Fluka and Rhône-Poulenc and used without further purification. The milling treatments were carried out either in a Retsch PM100 Planetary Mill or in a vibrating Retsch Mixer Mill 200. FTIR spectra were recorded on a Perkin-Elmer Spectrum 100 FT-IR spectrophotometer. ${ }^{1} \mathrm{H}$ NMR spectra were recorded on a Bruker Avance DPX $200 \mathrm{MHz}$ spectrometer and are reported in ppm using the solvent as the internal standard $\left(\mathrm{CDCl}_{3}\right.$ at $\left.7.24 \mathrm{ppm}\right)$. The NMR data are reported as follows: $\mathrm{s}=$ singlet, $\mathrm{d}=$ doublet, $\mathrm{t}=$ triplet, $\mathrm{m}=$ multiplet, $\mathrm{br}=$ broad; coupling constant in $\mathrm{Hz}$; integration. ${ }^{13} \mathrm{C}$ NMR spectra were recorded on a Bruker Avance AM $75 \mathrm{MHz}$ spectrometer and are reported in ppm using the solvent as the internal standard $\left(\mathrm{CDCl}_{3}\right.$ at $77.2 \mathrm{ppm})$. Analytical samples for NMR analysis were filtered through Rotilabo syringe filters (PTFE, unsterile, $0.20 \mu \mathrm{m}$ pore size). Mass spectra were obtained by LC-MS by means of ESI using a Water Alliance 2695 LC instrument coupled to a Waters ZQ spectrometer with an electrospray source, a simple quadrupole analyser and a UV Waters 2489 detector. HRMS analyses were performed with a Q-Tof (Waters, ESI, 2001) spectrometer. Enantiomeric excesses were measured by using a Beckman Coulter System Gold 126 Solvent Module HPLC machine and System Gold 168 Detector with a $4.6 \times 250 \mathrm{~mm}$ Daicel Chiralpak OD columns using $n$-hexane and 2-propanol as solvents. ICP-MS analyses were realised by the Service Central d'Analyse of the CNRS. Atomic absorption analyses were realised on a Philips Pye Unicam SP9 spectrometer. Samples were placed under an air/acetylene atmosphere.

\section{General procedure for the acylation of N-, O-, S- and C-nu- cleophiles}

The carboxylic acid $(1.5 \mathrm{mmol})$ and CDI $(243 \mathrm{mg}, 1.5 \mathrm{mmol})$ were introduced into a $12 \mathrm{~mL}$ stainless-steel grinding bowl with 50 stainless-steel balls ( $5 \mathrm{~mm}$ diameter). The bowl was closed and subjected to grinding for $5 \mathrm{~min}$ in the planetary ball mill operated at $500 \mathrm{rpm}$. Then the nucleophile $(1.35 \mathrm{mmol})$ was added. The bowl was closed and subjected to grinding for $10 \mathrm{~min}$ in the planetary ball mill operated at $500 \mathrm{rpm}$. Deionised water $(4 \mathrm{~mL})$ was added and the bowl was closed and subjected to grinding for $5 \mathrm{~min}$ in the planetary ball mill operated at $500 \mathrm{rpm}$. After this treatment, the resulting fine suspension was filtered, washed with deionised water and then dried under vacuum over $\mathrm{P}_{2} \mathrm{O}_{5}$ to obtain the final product.

\section{Synthesis of $\mathbf{N}$-benzylhydrocinnamide}

Following the general procedure, 3-phenylpropionic acid $(0.225 \mathrm{~g}$ $1.5 \mathrm{mmol}$ ) was used as the acid and benzylamine hydrochloride $(0.194 \mathrm{~g}, 1.35 \mathrm{mmol})$ as the nucleophile. $\mathrm{N}$-Benzylhydrocinnamide was recovered as a white solid $(0.302 \mathrm{~g}, 94 \%)$. M.p. $79-80^{\circ} \mathrm{C}$ (lit.. ${ }^{[30]}$ $\left.80^{\circ} \mathrm{C}\right) ;{ }^{1} \mathrm{H}$ NMR $\left(200 \mathrm{MHz}, \mathrm{CDCl}_{3}\right): \delta=7.38-7.12(\mathrm{~m}, 10 \mathrm{H}), 5.60$ (brs, $1 \mathrm{H}), 4.42(\mathrm{~d}, J=5.7 \mathrm{~Hz}, 2 \mathrm{H}), 3.03(\mathrm{t}, J=7.6 \mathrm{~Hz}, 2 \mathrm{H}), 2.54 \mathrm{ppm}(\mathrm{t}, J=$ $7.6 \mathrm{~Hz}, 2 \mathrm{H}) ;{ }^{13} \mathrm{C}$ NMR $\left(75 \mathrm{MHz}, \mathrm{CDCl}_{3}\right): \delta=172.1,140.9,138.3,128.7$, 128.6, 128.5, 127.8, 127.5, 126.3, 43.6, 38.5, 31.8 ppm; MS (ESI): $\mathrm{m} / \mathrm{z}$ : $240.1[\mathrm{M}+\mathrm{H}]^{+}$.

\section{Synthesis of $\mathrm{N}$-benzylbenzamide on a $\mathbf{2 2 . 5} \mathrm{mmol}$ scale with rubber balls}

Benzoic acid $(3.053 \mathrm{~g}, 25 \mathrm{mmol})$ and $\mathrm{CDI}(4.062 \mathrm{~g}, 25 \mathrm{mmol})$ were introduced into a $250 \mathrm{~mL}$ stainless-steel grinding bowl with 10 rubber balls ( $18 \mathrm{~mm}$ diameter). The bowl was closed and subjected to grinding for $5 \mathrm{~min}$ in the planetary ball mill operated at $500 \mathrm{rpm}$. Then benzylamine hydrochloride $(3.231 \mathrm{~g}, 22.5 \mathrm{mmol})$ was added. The bowl was closed and subjected to grinding for $10 \mathrm{~min}$ in the planetary ball mill operated at $500 \mathrm{rpm}$. Deionised water $(40 \mathrm{~mL})$ was added and the bowl was closed and subjected to grinding for $5 \mathrm{~min}$ in the planetary ball mill operated at $500 \mathrm{rpm}$. After this treatment, the fine suspension was transferred onto a glass frit, washed with deionised water and dried under vacuum over $\mathrm{P}_{2} \mathrm{O}_{5}$ to obtain $\mathrm{N}$-benzylbenzamide as a white solid $(4.33 \mathrm{~g}, 91 \%$, corrected yield based on the content of contaminant). M.p. $104-105^{\circ} \mathrm{C}$ (lit.. ${ }^{[31]} 104^{\circ} \mathrm{C}$ ); ${ }^{1} \mathrm{H}$ NMR $\left(200 \mathrm{MHz}, \mathrm{CDCl}_{3}\right)$ : $\delta=7.82-7.73(\mathrm{~m}, 2 \mathrm{H}), 7.53-7.22(\mathrm{~m}, 8 \mathrm{H}), 6.38(\mathrm{brs}, 1 \mathrm{H}), 4.64 \mathrm{ppm}$ (d, $J=5.7 \mathrm{~Hz}, 2 \mathrm{H}) ;{ }^{13} \mathrm{C}$ NMR $\left(75 \mathrm{MHz}, \mathrm{CDCl}_{3}\right): \delta=167.8,138.4,134.6$, 131.8, 129.0, 128.8, 128.1, 127.8, 127.2, 44.3 ppm; MS (ESI): $\mathrm{m} /$ $z: 212.2[M+H]^{+}$.

\section{Synthesis of Teriflunomide ${ }^{[32]}$}

5-Methylisoxazole-4-carboxylic acid (191 mg, $1.5 \mathrm{mmol}$ ) and CDI $(243 \mathrm{mg}, 1.5 \mathrm{mmol})$ were introduced into stainless-steel grinding bowl with 50 stainless-steel balls ( $5 \mathrm{~mm}$ diameter). The bowl was closed and subjected to grinding for $20 \mathrm{~min}$ in the planetary ball mill operated at $500 \mathrm{rpm}$. Then 4-trifluoromethylaniline hydrochloride ( $267 \mathrm{mg}, 1.35 \mathrm{mmol}$ ) was added. The bowl was closed and subjected to grinding for $5 \mathrm{~h}$ in the planetary ball mill operated at $500 \mathrm{rpm}$, with $1 \mathrm{~min}$ break every $10 \mathrm{~min}$ and inversion of the rotation direction after each break. Deionised water $(4 \mathrm{~mL})$ was added and the bowl was closed and subjected to grinding for $5 \mathrm{~min}$ in the planetary ball mill operated at $500 \mathrm{rpm}$. After this treatment, the fine suspension was transferred to a round-bottomed flask, the $\mathrm{pH}$ was adjusted to 1 with concentrated hydrochloric acid and the suspension was stirred with a magnetic stirrer for $24 \mathrm{~h}$. The suspension was then filtered and dried under vacuum over $\mathrm{P}_{2} \mathrm{O}_{5}$ to obtain a white solid. 2-Cyano-3-hydroxy- $\mathrm{N}$-(4-trifluoromethylphenyl)-2-butenamide (Teriflunomide) as the major tautomer was recovered as a white solid $(0.297 \mathrm{~g}, 81 \%)$. M.p. $230-232^{\circ} \mathrm{C}$; ${ }^{1} \mathrm{H}$ NMR (200 MHz, [D $\mathrm{D}_{6}$ DMSO): $\delta=10.97(\mathrm{~m}, 2 \mathrm{H}), 7.75(\mathrm{~d}, J=8.5 \mathrm{~Hz}, 2 \mathrm{H})$, $7.64(\mathrm{~d}, J=7.6 \mathrm{~Hz}, 2 \mathrm{H}), 2.23 \mathrm{ppm}(\mathrm{s}, 3 \mathrm{H}) ;{ }^{13} \mathrm{C} \mathrm{NMR}(150 \mathrm{MHz}$, [D $\mathrm{D}_{6}$ ]DMSO): $\delta=187.3,166.5,142.1,126.3,126.0,123.7,123.3,122.7$, $120.7,120.2,119.4,80.5,23.9$ ppm; MS (ESI): $\mathrm{m} / \mathrm{z}: 271[\mathrm{M+H}]^{+}$.

\section{Acknowledgements}

The CNRS and Université Montpellier (post-doctoral grant to J.B.) are acknowledged for their financial support. François 
Métro is warmly acknowledged for production of the graphical abstract.

Keywords: acylation - amides • green chemistry mechanochemistry $\cdot$ solvent-free synthesis

[1] a) N. I. Vasilevich, R. V. Kombarov, D. V. Genis, M. A. Kirpichenok, J. Med. Chem. 2012, 55, 7003-7009; b) J. S. Carey, D. Laffan, C. Thomson, M. T. Williams, Org. Biomol. Chem. 2006, 4, 2337-2347.

[2] D. S. MacMillan, J. Murray, H. F. Sneddon, C. Jamieson, A. J. B. Watson, Green Chem. 2013, 15, 596-600.

[3] C. Jimenez-Gonzalez, C. S. Ponder, Q. B. Broxterman, J. B. Manley, Org. Process Res. Dev. 2011, 15, 912-917.

[4] a) S. L. James, C. J. Adams, C. Bolm, D. Braga, P. Collier, T. Friščić, F. Grepioni, K. D. M. Harris, G. Hyett, W. Jones, A. Krebs, J. Mack, L. Maini, A. G. Orpen, I. P. Parkin, W. C. Shearouse, J. W. Steed, D. C. Waddell, Chem. Soc. Rev. 2012, 41, 413-447; b) E. Boldyreva, Chem. Soc. Rev. 2013, 42, 7719-7738; c) T. Friščić, S. L. James, E. V. Boldyreva, C. Bolm, W. Jones, J. Mack, J. W. Steed, K. S. Suslick, Chem. Commun. 2015, 51, 6248-6256.

[5] I. Huskić, I. Halasz, T. Friščić, H. Vančik, Green Chem. 2012, 14, $1597-$ 1600.

[6] a) G. Kaupp, J. Schmeyers, M. R. Naimi-Jamal, H. Zoz, H. Ren, Chem. Eng. Sci. 2002, 57, 763-765; b) G. Kaupp, M. R. Naimi-Jamal, V. Stepanenko, Chem. Eur. J. 2003, 9, 4156-4161; c) G. Kaupp, M. Reza Naimi-Jamal, J. Schmeyers, Tetrahedron 2003, 59, 3753-3760; d) G. Kaupp, CrystEngComm 2006, 8, 794-804; e) P. Nun, C. Martin, J. Martinez, F. Lamaty, Tet rahedron 2011, 67, 8187-8194; f) M. Ferguson, N. Giri, X. Huang, D. Apperley, S. L. James, Green Chem. 2014, 16, 1374-1382.

[7] a) Z. Zhang, Y.-W. Dong, G.-W. Wang, K. Komatsu, Synlett 2004, 61-64; b) Z. Zhang, Y.-W. Dong, G.-W. Wang, K. Komatsu, Chem. Lett. 2004, 33, 168-169; c) V. Declerck, P. Nun, J. Martinez, F. Lamaty, Angew. Chem. Int. Ed. 2009, 48, 9318-9321; Angew. Chem. 2009, 121, 9482-9485; d) M. R. Naimi-Jamal, J. Mokhtari, M. G. Dekamin, G. Kaupp, Eur. J. Org. Chem. 2009, 3567-3572; e) L. Konnert, A. Gauliard, F. Lamaty, J. Martinez, E. Colacino, ACS Sustainable Chem. Eng. 2013, 1, 1186-1191; f) D. Tan, C. Mottillo, A. D. Katsenis, V. Štrukil, T. Friščić, Angew. Chem. Int. Ed. 2014, 53, 9321 -9324; Angew. Chem. 2014, 126, 9475-9478; g) D. Tan, V. Štrukil, C. Mottillo, T. Friščić, Chem. Commun. 2014, 50, 5248-5250.

[8] V. Štrukil, B. Bartolec, T. Portada, I. Đilović, I. Halasz, D. Margetić, Chem. Commun. 2012, 48, 12100-12102.

[9] With the exception of ref. [8] in which nitromethane was used during the process.

[10] C. F. Burmeister, A. Kwade, Chem. Soc. Rev. 2013, 42, 7660-7667.

[11] a) R. Thorwirth, F. Bernhardt, A. Stolle, B. Ondruschka, J. Asghari, Chem. Eur. J. 2010, 16, 13236-13242; b) T. L. Cook, J. A. Walker, J. Mack, Green Chem. 2013, 15, 617-619; c) D. W. Peters, R. G. Blair, Faraday Discuss. 2014, 170, 83-91; d) D. A. Fulmer, W. C. Shearouse, S. T. Medonza, J. Mack, Green Chem. 2009, 11, 1821-1825.

[12] T.-X. Métro, J. Bonnamour, T. Reidon, J. Sarpoulet, J. Martinez, F. Lamaty, Chem. Commun. 2012, 48, 11781-11783.
[13] a) J. Bonnamour, T.-X. Métro, J. Martinez, F. Lamaty, Green Chem. 2013 15, 1116-1120; b) T.-X. Métro, X. J. Salom-Roig, M. Reverte, J. Martinez, F. Lamaty, Green Chem. 2015, 17, 204-208; c) T.-X. Métro, E. Colacino, J. Martinez, F. Lamaty, in Ball Milling Towards Green Synthesis: Applications, Projects, Challenges, The Royal Society of Chemistry, Cambridge, 2015, pp. $114-150$.

[14] For previous examples of ex situ analysis, see reference [7c] and : a) $X$ Ma, W. Yuan, S. E. J. Bell, S. L. James, Chem. Commun. 2014, 50, $1585-$ 1587; b) I. A. Tumanov, A. F. Achkasov, E. V. Boldyreva, V. V. Boldyrev, CrystEngComm 2011, 13, 2213-2216; for previous examples of in situ analysis, see: c) A. D. Katsenis, A. Puškarić, V. Štrukil, C. Mottillo, P. A. Julien, K. Užarević, M.-H. Pham, T.-O. Do, S. A. J. Kimber, P. Lazić, O. Magdysyuk, R. E. Dinnebier, I. Halasz, T. Friščić, Nat. Commun. 2015, 6, 6662; d) D. Gracin, V. Štrukil, T. Friščić, I. Halasz, K. Užarević, Angew. Chem. Int. Ed. 2014, 53, 6193-6197; Angew. Chem. 2014, 126, 6307-6311.

[15] Supplier material analysis indicates the following content of the stainless-steel jars (in \%): Fe (82.925), Cr (14.5), Mn (1), Si (1), C (0.5), P (0.045), $\mathrm{S}$ (0.03). For the jar made of agate: $\mathrm{SiO}_{2}(99.91), \mathrm{Al}_{2} \mathrm{O}_{3}(0.02)$, $\mathrm{Na}_{2} \mathrm{O}(0.02), \mathrm{Fe}_{2} \mathrm{O}_{3}(0.01), \mathrm{K}_{2} \mathrm{O}(0.01), \mathrm{MnO}(0.01), \mathrm{MgO}(0.01), \mathrm{CaO}(0.01)$

[16] Corrected yield based on the content of contaminant.

[17] R. K. Mylavarapu, G. C. M. Kondaiah, N. Kolla, R. Veeramalla, P. Koilkonda, A. Bhattacharya, R. Bandichhor, Org. Process Res. Dev. 2007, 11, $1065-$ 1068.

[18] E. K. Woodman, J. G. K. Chaffey, P. A. Hopes, D. R. J. Hose, J. P. Gilday, Org. Process Res. Dev. 2009, 13, 106-113.

[19] P. J. Dunn, W. Hoffmann, Y. Kang, J. C. Mitchell, M. J. Snowden, Org. Process Res. Dev. 2005, 9, 956-961.

[20] D. Magne, F. Mézin, G. Palmer, P. A. Guerne, Inflammation Res. 2006, 55, 469-475.

[21] P. O'Connor, J.S. Wolinsky, C. Confavreux, G. Comi, L. Kappos, T. P. Olsson, H. Benzerdjeb, P. Truffinet, L. Wang, A. Miller, M. S. Freedman, N. Engl. J. Med. 2011, 365, $1293-1303$.

[22] K. Arnold, A. S. Batsanov, B. Davies, A. Whiting, Green Chem. 2008, 10, $124-134$.

[23] J. C. Sheehan, G. P. Hess, J. Am. Chem. Soc. 1955, 77, 1067-1068.

[24] G. Chattopadhyay, S. Chakraborty, C. Saha, Synth. Commun. 2008, 38, $4068-4075$.

[25] R. Paul, G. W. Anderson, J. Am. Chem. Soc. 1960, 82, 4596-4600.

[26] P. S. Chaudhari, S. D. Salim, R. V. Sawant, K. G. Akamanchi, Green Chem. 2010, 12, 1707-1710.

[27] R. A. Sheldon, Green Chem. 2007, 9, 1273-1283.

[28] K. Van Aken, L. Strekowski, L. Patiny, Beilstein J. Org. Chem. 2006, 2, 3.

[29] F. Roschangar, R. A. Sheldon, C. H. Senanayake, Green Chem. 2015, 17, $752-768$.

[30] I. Shiina, Y.-I. Kawakita, Tetrahedron 2004, 60, 4729-4733.

[31] T. Maki, K. Ishihara, H. Yamamoto, Org. Lett. 2006, 8, 1431-1434.

[32] K. Deo, S. Patel, S. Dhol, S. Sanghani, V. Ray, 2011, US20110105795. 